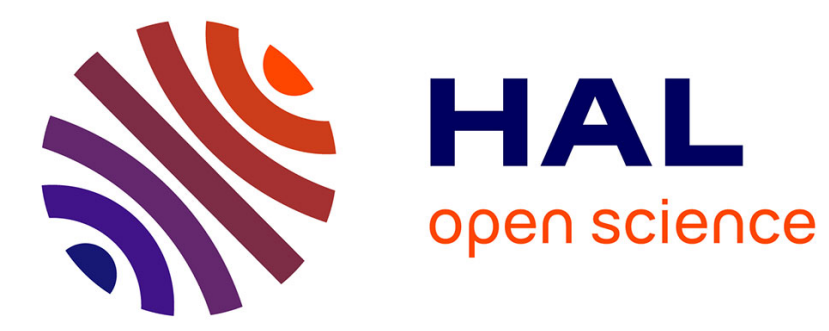

\title{
3D printing of silica glass through a multiphoton polymerization process
}

Thomas Doualle, Jean-Claude André, Laurent Gallais

\section{To cite this version:}

Thomas Doualle, Jean-Claude André, Laurent Gallais. 3D printing of silica glass through a multiphoton polymerization process. Optics Letters, 2021, 46 (2), pp.364-367. 10.1364/OL.414848 . hal-03200006

\section{HAL Id: hal-03200006 https://hal.science/hal-03200006}

Submitted on 25 Feb 2022

HAL is a multi-disciplinary open access archive for the deposit and dissemination of scientific research documents, whether they are published or not. The documents may come from teaching and research institutions in France or abroad, or from public or private research centers.
L'archive ouverte pluridisciplinaire HAL, est destinée au dépôt et à la diffusion de documents scientifiques de niveau recherche, publiés ou non, émanant des établissements d'enseignement et de recherche français ou étrangers, des laboratoires publics ou privés. 


\title{
3D-printing of silica glass through multiphoton polymerization process
}

\author{
Thomas Doualle, ${ }^{1}$ Jean-Claude Andre, ${ }^{2}$ Laurent Gallais ${ }^{1, *}$
}

\author{
${ }^{1}$ Aix Marseille Univ, CNRS, Centrale Marseille, Institut Fresnel, France \\ ${ }^{2}$ CNRS, Université de Lorraine, LRGP, Nancy, France \\ *Corresponding author: laurent.gallais@fresnel.fr
}

Received XX Month XXXX; revised XX Month, XXXX; accepted XX Month XXXX; posted XX Month XXXX (Doc. ID XXXXX); published XX Month XXXX

\begin{abstract}
We introduce a laser-based process relying on multi-photon induced polymerization to produce complex 3D glass parts. A focused, intense, laser beam is used to polymerize a transparent resin, loaded with additives and silica nanoparticles, at the wavelength of the laser beam through non-linear absorption processes. The object is created directly in the volume, overcoming the limitation of layer-by-layer process. The process enables the production of silica parts with consecutive debinding and sintering processes. 3D objects of centimetric dimensions are obtained with bulk silica density and a resolution that depends on the laser spot size.
\end{abstract}

It is difficult, and sometimes even impossible, to achieve glass objects with conventional glass processing techniques because of their scales (sub-millimeter length) or their configurations. Additive manufacturing of glass-based material allows building new functional glass materials with tailored properties and high resolution. Moreover, glass-based materials hold the potential to provide particular value in the additive manufacturing field due to their hardness, optical qualities, affordability and availability. There have been significant advances in the last few years to develop innovative processes to print 3D glass structures. For example, binder jetting, selective laser melting and sintering of glass powders approaches have been applied to glass materials in order to overcome their high melting temperatures and high viscosity [1-5]. With this method, the sintered glasses can be very fragile and appear opaque due to incomplete densification. Methods to print glass directly require high temperatures: for fused deposition molding approach [6], soda lime glass is heated to around $1000{ }^{\circ} \mathrm{C}$ and for filament feed technique a manual wire feeding approach is used in which a glass filament is melted using a laser [7]. In both these processes, filaments are potentially vulnerable to thermal stresses and unable to completely merge into the desired structure, which give coarse structures with high surface. However, it is also possible to overcome these heat treatments limitations. In fact, Nguyen et al. developed a two steps process (forming and sintering) which uses direct ink writing for the 3D printing of optically transparent glass structures with sub-millimeter features [8]. From photo-curable silica nanocomposite, stereo-lithography 3D technique combined with sintering process can also produce transparent fused silica glass components [9]. Recently, Kotz et al. have presented research which allow to print non-porous silica glasses, with the optical transparency of commercial fused silica glass, and a smooth surface with a roughness of a few nanometers [10]. This work was enabled by the development of glass nanocomposites which can be cured by light and sequentially thermally annealed to result in highlytransparent fused silica glass [11], which has opened new perspectives such 3D printing of silica preform [12]. Other approaches exploit the photopolymerization-induced phase separation of hybrid resins [13] or hybrid ceramic precursor that can undergo both the photopolymerization reaction and a sol-gel process [14], to create transparent silica parts from a solution form, without any particles.

The common approach in these works to build arbitrarily-shaped parts with current 3D printing technologies is to create multiple 2D slices and then stack these slices to form 3D objects. This layer-by-layer process has numerous limitations: manufacturing time, mechanical anisotropy properties, shrinkage, shear stress, robust implementation time of layers of constant thickness, need for the creation of supports for complex parts and their elimination in a post processing operation, etc [15]. Most of these drawbacks are linked to the layer by layer procedure. The direct creation of 3D structures is however possible with TwoPhoton Polymerization (TPP) technique [16]; polymerization is activated by the simultaneous absorption of two photons of an intense laser radiation, only taking place at high laser intensity within a spatially localized focal spot in the monomer with photosensitive initiator. Then, with the TPP technique, it is possible to polymerize volumes inside the polymer liquids contrary to conventional one-photon-based process (such as stereo-lithography [17]), in which polymerization takes place only on the liquid surface or close to. TPP can directly produce 3D nanostructures, with a spatial resolution far beyond the diffraction limit. It is widely applied in fields such as micro/nano-photonics $[18,19]$, fabrication and rapid prototyping of different photonic structures and integrated optics [20,21], micro-electro-mechanical systems (MEMS) and micro-components [22, 23], microfluidics [24] or biomedical [2527].

It will be therefore of high interest to apply the TPP technique to the direct production of 3D glass components. In this context we introduce in this letter a multi-step process (preparation of mixtures, 3D printing through TPP and post-treatments) which requires simple materials to prepare glass nanocomposites and equipment to fabricate transparent silica glass from a green part printed with two photon polymerization process.

The critical point in this process is the preparation of mixtures that should contain a high amount of silica nanoparticles, have a high 
viscosity in order to build the 3D part without deformation (internal shrinkage and fall of the free object under construction in accordance with Stokes' law), be transparent at the laser operating wavelength (both initial and polymerized material) and be absorbent at half the laser wavelength to initiate the polymerization process. We have prepared mixture of $80 \mathrm{wt} \%$ monomer hydroxyl-ethyl-methacrylate (HEMA) and $20 \mathrm{wt} \%$ of solvent phenoxyethanol (POE), loaded with nanoparticles from commercial hydrophilic fumed silica ("Aerosil OX50" from Evonik, Germany), with a mean diameter of $40 \mathrm{~nm}$. With such a composition it is possible to disperse a high amount of silica nanoparticles [28]. In our case the nanoparticles are dispersed in the mixture in small increments with a mechanical stirrer until reaching 50 $w t \%$ of nanoparticles of silica. The solvent phenoxyethanol is added to form a solvation layer around the particles leading to a stable sol and high solid loading without prior particle modification or the use of dispersants. A photo-initiator (2,2-Dimethoxy-2-phenylacetophenone) (1 wt\%) is added to the dispersion to initiate the two-photon polymerization in the UV. The slurry obtained is transparent in the visible spectral range, as illustrated on the experiment shown on Figure 1, and it has a high viscosity estimated to be greater than $5 \mathrm{~Pa}$ s (from comparison to commercial high viscosity photocurable resins).

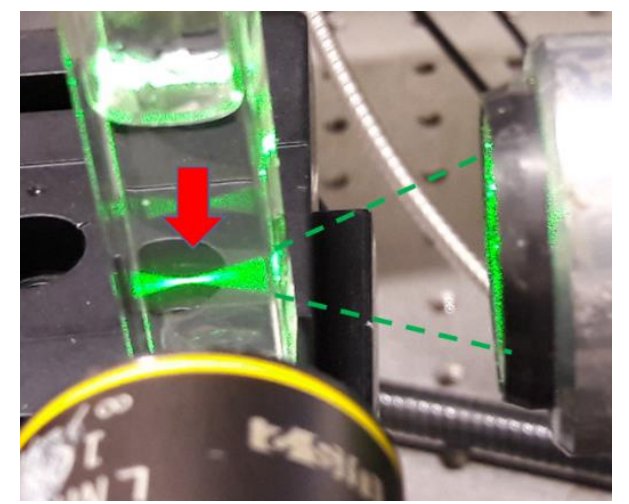

Figure 1: Two-Photon Polymerization of the mixture loaded with silica nanoparticles. A $515 \mathrm{~nm}$ laser beam is focused inside the mixture with a long working distance microscope objective, polymerization occurs at the focus point, indicated by the red arrow.

A schematic of the developed 3D printing laser system developed is shown in Figure 2. The laser source is a commercial femtosecond diode pumped Ytterbium amplified laser operating at $1030 \mathrm{~nm}$, with a repetition rate of $1 \mathrm{kHz}$. For the experiments described in this paper, $515 \mathrm{~nm}$ pulses are obtained by second harmonic generation in a nonlinear crystal. The average laser power is controlled with a polarizer combined with a half-wave plate. The laser beam passes through an optic to shape the beam inside the preparation contained by a transparent tank. Optionally a beam shaper is used in the set-up to adjust the desired voxel morphology. An imaging system is used to monitor the process in real time. The stages, visualization system, halfwave plate and shutter are connected to a computer for monitoring and synchronization. A commercial laser machining software is used to generate the movements of the reactor vessel from a CAD file and control the synchronization with the laser irradiation.

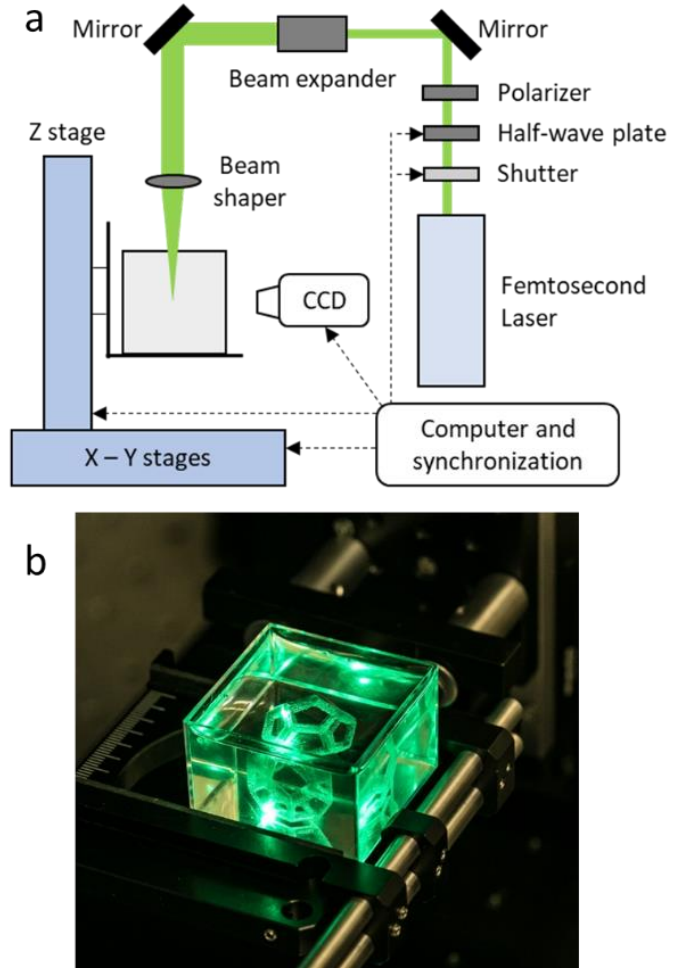

Figure 2: 3D printing system configuration. a: schematic of the experimental arrangement; b: 3D printing of a complex part in the mixture on our experimental set-up.

We were able to vary the dimensions of the formed voxel during the laser irradiation by variation of the laser power. Figure 3 shows the influence of the laser power and duration applied in a resin on the voxel length formed. In these conditions, we are able to produce voxel from few tens of $\mu \mathrm{m}$ of length to several hundreds of $\mu \mathrm{m}$.

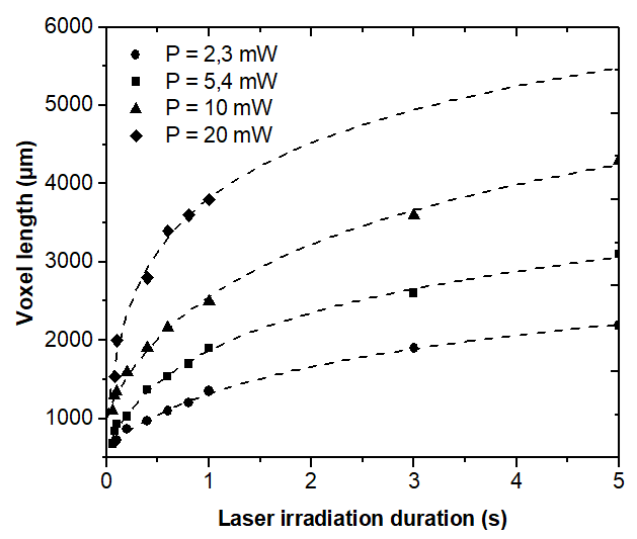

Figure 3: Voxel length as a function of applied power and duration of exposition in conditions.

After the 3D printing process, solidified structures are picked out of the tank and rinsed with isopropyl alcohol to remove the non-polymerized material and the nanoparticles. It is then necessary to apply thermal post-treatments to transform the polymerized green parts into silica glass: debinding and sintering precise procedures are performed in a high temperature furnace. These procedures are optimized to produce silica glass objects with the highest optical quality possible. The purpose is to obtain a final transparent part, without remaining porosity and 
cracks, and which presents a density as close as possible to the theoretical density of silica $\left(2.2 \mathrm{~g} / \mathrm{cm}^{3}\right)$.

Thermal debinding step consists in removing by evaporation/pyrolysis the organic binders and the water molecules from the printed green part. This stage is crucial and has a huge impact on the final parts. On the one hand, if the polymeric matrix elimination is too fast, cracks and breaks will appear on the object. On the other hand, defects like large voids or blisters can also occur in the case of non-optimized debinding and will constitute a source of contamination and affect the mechanical properties of the final component. To avoid these issues, long heating cycles and holding phases are often used to give the polymer enough time to decompose and evaporate out of the part [10]. We have used thermogravimetric analysis (TGA) and we have conducted a parametric study to evaluate the thermal debinding kinetics of 3D parts in order to define an optimized protocol. As can be seen in Figure 4a the TGA measurements showed two different turning points corresponding to the different phases of weight loss: the major decomposition step results in weight loss of $\sim 43 \%$ between $25^{\circ} \mathrm{C}$ and $150^{\circ} \mathrm{C}$ and the second weight loss of $\sim 5 \%$ is around $400^{\circ} \mathrm{C}$. To confront and validate these results, we carried out a parametric study: different temperature rises, holdings temperatures and durations were tested. From these results, we built our debinding protocol, presented in Figure 4b. Thermal debinding and sintering are performed in a high temperature tube furnace (type STF $15 / 180$, Carbolite). The brown part is debinded at $600{ }^{\circ} \mathrm{C}$ during $2 \mathrm{~h}$ (heating rate of $0.2^{\circ} \mathrm{C} \mathrm{min}-1$ ) for organic matter removal.
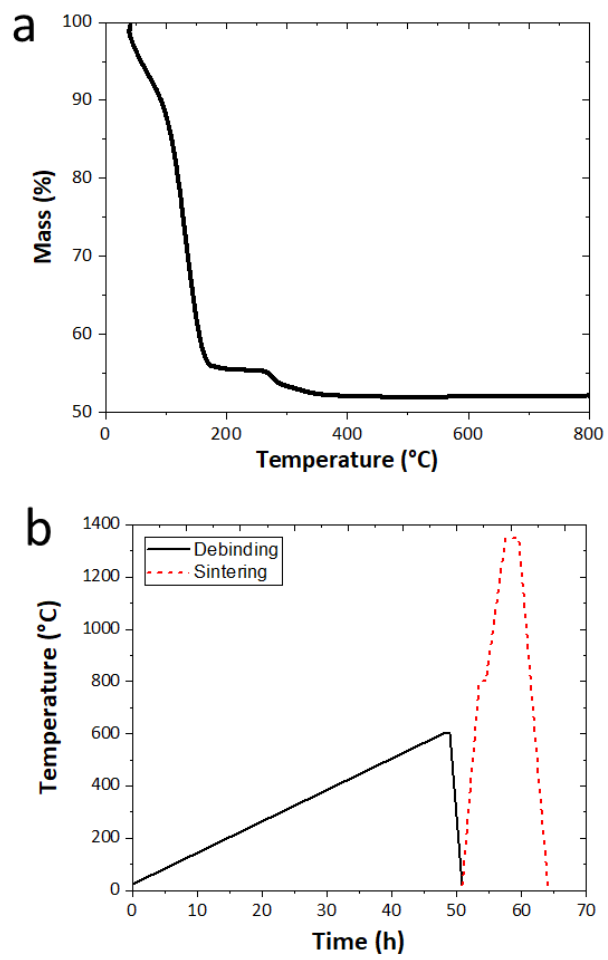

Figure 4: Thermal processing. a) Thermogravimetric analysis of a silica glass sample printed from a resin loaded with $50 \%$ wt of nanoparticles of silica. b) Optimized debinding and sintering protocol.

After this thermal debinding, only the silica powder remains, resulting in the "brown part". The final step of sintering allows a capillary contraction and rearrangement of solid silica nanoparticles to increase the density and, in principle, obtain high-quality fused silica glass with no remaining porosity and no cracks. Thus, we investigated sintering parameters to find the optimum conditions. The highest density was found at $1360{ }^{\circ} \mathrm{C}$ with a holding phase of $2 \mathrm{~h}$ and a heating rate of 3 ${ }^{\circ} \mathrm{C} / \mathrm{min}$. To evaporate molecularly bound water and surface bound silanol groups, we apply a holding phase of $2 \mathrm{~h}$ at $800^{\circ} \mathrm{C}$ (heating rate of $5{ }^{\circ} \mathrm{C} / \mathrm{min}$ ) before sintering. The final heating pattern (debinding and sintering) is presented in the Figure $4 \mathrm{~b}$. During the experimental investigations, we note the influence of the sample depth on the density of the parts obtained (Figure 5a): for same sintering conditions, the thinner the sample, the better the density. Moreover, the effect of sintering atmosphere was investigated to optimize the optical transparency and the density of the sintered parts. It has been found that parts obtained with sintering under air atmosphere presents poor transparency with a low density $(<2.0 \mathrm{~g} / \mathrm{cm} 3)$. This is due to the fact that atmospheric conditions lead partially non-sintered areas due to the entrapped air or gas. This effect is illustrated in Figure 5b, which is a scanning electron microscopy observation of air bubbles trapped in a part sintered under atmospheric condition. In order to decrease porosity and enhance the density of the parts, we achieve our sintering under vacuum $\left(5 \times 10^{-2} \mathrm{mbar}\right)$. In such conditions, the transparency has been characterized for different sample thicknesses (Figure 5a): the transmission has been measured in the 500-1500 nm range and compared to a commercial fused silica substrate ( $5 \mathrm{~mm}$ thick). The transparency is close to the theoretical one for thicknesses lower than 3 mm ( 0.91 for the printed part, versus 0.93 for the substrate), but for thicker parts some bubbles are still remaining which lead to scattering and lower density, meaning that the process still needs to be optimized for thick parts.
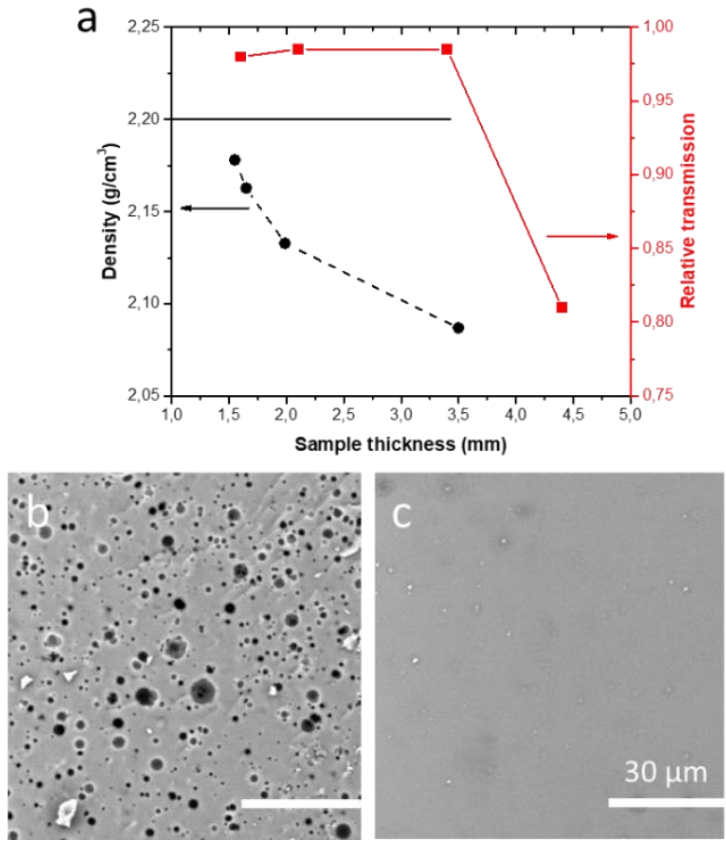

Figure 5: Material characterization after sintering. a) Influence of the sample depth on the obtained density and transparency (relative transmission in the $500-1500 \mathrm{~nm}$ range compared to fused silica). Dashed line represents the theoretical density value of the amorphous silica density. b) SEM observations of the air trapped in the silica glass when sintering is done under atmospheric condition. c) SEM observations in the case of sintering step in vacuum environment.

The objects presented in the Figure 6 have been made through the described protocol. After printing and rinsing, green parts were debinded and sintered with the optimized temperature profile shown 
in Figure 4b. We have obtained transparent parts, without cracks and breakages. The measured density of the sample treated with the presented thermal post-treatments is $2.18 \mathrm{~g} / \mathrm{cm} 3$, close to the theoretical value of amorphous silica. Therefore, such samples are sintered to around $99 \%$ density. The linear shrinkages $\Delta \mathrm{L}$ on samples was calculated as the variation of the external dimensions of the parts. It is not dependent on the scale of the parts but only on the initial fraction of silica nanoparticles in the mixture, that we have considered during the dimensioning of the parts. In these cases, we have found a homogeneous linear shrinkage $\Delta \mathrm{L}$ of $30 \%$. The experimental arrangement has been built to print objects in comparable dimensions to standard UV lithography, but it should be noted that using microstereolithography, fused silica glass objects with tens of microns resolution have been successfully been printed as shown in Ref. [29], which suggests the possibility to downscale voxel size and object size.

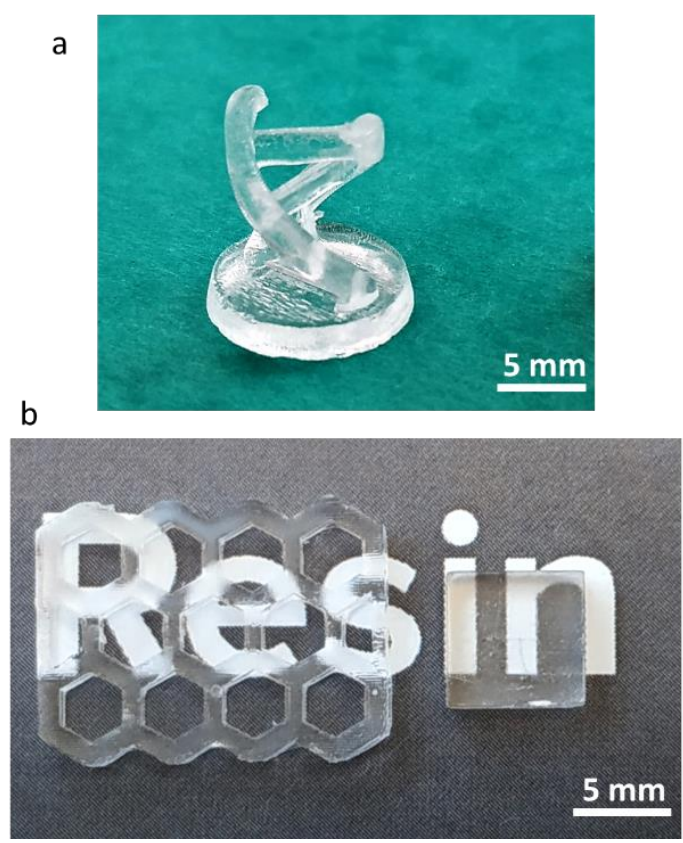

Figure 6: Examples of printed and sintered silica glass parts.

In conclusion, we have developed an original and efficient process to produce complex silica glass parts. A focused, pulsed laser beam with a high flux density is used to polymerize a transparent mixture, containing silica nanoparticles, through nonlinear absorption processes. Thus, we can create objects directly in the volume, avoiding the addition of successive layers and its limitations. To obtain silica glass parts, with density close to the theoretical one of amorphous silica and without remaining porosity and cracks, we specifically optimized the thermal post-treatments and showed the importance of them on the success of the global process. Further work is of course required to optimize the process, particularly surface quality to obtain lower roughness, but this proof of concept could enable new applications in photonics and fields requiring fast prototyping of silica parts.

Acknowledgments. The authors would like to thank Thierry Chartier, from Institut de Recherche sur les Céramiques (Limoges, France) for relevant advices on this work.

Disclosures. The authors declare no conflicts of interest.
1. F. Klocke, A. McClung, C. Ader, in Solid Freeform Fabrication Proceedings 2004, 214.

2. G. Marchelli, R. Prabhakar, D. Storti, M. Ganter, Rapid Prototyping Journal 17, 187 (2011).

3. J. Luo, H. Pan, E. Kinzel, Journal of Manufacturing Science and Engineering 136, 061024 (2014).

4. M. Fateri, A. Gebhardt, International Journal of Applied Ceramic Technology 12, 53 (2015).

5. K. C. Datsiou, E. Saleh, F. Spirrett, R. Goodridge, I. Ashcroft, D. Eustice, Journal of the American Ceramic Society 102, 4410 (2019)

6. J. Klein, M. Stern, G. Franchin, M. Kayser, C. Inamura, S. Dave, J. C. Weaver, P. Houk, P. Colombo, M. Yang, N. Oxman, 3D Printing and Additive Manufacturing. 2, 92 (2015).

7. J. Luo, L. J. Gilbert, C. Qu, R. G. Landers, D. A. Bristow, E. C. Kinzel, J. Manuf. Sci. Eng. 139, 061006 (2017).

8. D. T. Nguyen, C. Meyers, T. D. Yee, N. A. Dudukovic, J. F. Destino, C. Zhu, E. B. Duoss, T. F. Baumann, T. Suratwala, J. E. Smay, R. Dylla-Spears, Adv. Mater. 1701181 (2017).

9. M. Wozniak, T. Graule, Y. Hazan, D. Kata, J. Lis, Journal of the European Ceramic Society 29, 2259 (2009).

10. F. Kotz, K. Arnold, W. Bauer, D. Schild, N. Keller, K. Sachsenheimer, T. M. Nargang, C. Richter, D. Helmer, B. E. Rapp, Nature 544, 337 (2017).

11. F. Kotz, K. Plewa, W. Bauer, N. Schneider, N. Keller, T. Nargang, D. Helmer, K. Sachsenheimer, M. Schäfer, M. Worgull, C. Greiner, C. Richter, B. E. Rapp, Adv. Mater. 28, 4646 (2016).

12. Y. Chu, X. Fu, Y. Luo, J. Canning, Y. Tian, K. Cook, J. Zhang, G.-D. Peng, Opt. Lett. 44, 5358 (2019)

13. D.G. Moore, L. Barbera, K. Masania, A.R. Studart, Nat. Mater. 19, 212 (2020).

14. I. Cooperstein, E. Shukrun, O. Press, A. Kamyshny, S. Magdassi, ACS Appl. Mater. Interfaces 10, 18879 (2018)

15. J.C. André, From Additive Manufacturing to 3D/4D Printing 2: Current Techniques, Improvements and their Limitations, Wiley-ISTE, 2017.

16. S. Maruo, O. Nakamura, S. Kawata, Opt. Lett. 22, 132 (1997).

17. J.C. André, A. Le Méhauté, O. De Witte, patent FR2567668 (1984), 1984.

18. H.B. Sun, S. Matsuo, H. Misawa, Appl. Phys. Lett. 74, 786 (1999).

19. J. Scrimgeour, D. N. Sharp, C. F. Blanford, O. M. Roche, R. G. Denning, A. J. Turberfield, Adv. Mater. 18, 1557 (2006).

20. R. A. Borisov, G. N. Dorojkina, N. I. Koroteev, V. M. Kozenkov, S. A. Magnitskii, D. V. Malakhov, A. V.Tarasishin, and A. M. Zheltikov, Laser Phys. 8, 1105 (1998).

21. J. Serbin, A. Egbert, A. Ostendorf, B. N. Chichkov, R. Houbertz, G. Domann, J. Schulz, C. Cronauer, L. Fröhlich, M. Popall, Opt. Lett. 28, 301 (2003).

22. H.-B. Sun, S. Kawata, J. Lightwave Tech. 21, 624 (2003).

23. S. Maruo, K. Ikuta, H. Korogi, J. of Microelectromechanical Systems 12, $533(2003)$.

24. D. Wu, Q. D. Chen, L. G. Niu, J. N. Wang, J. Wang, R. Wang, H. Xia, H. B. Sun, Lab Chip 9, 2391S (2009).

25. P. Tayalia, C. R. Mendonca, T. Baldacchini, D. J. Mooney, E. Mazur, Adv. Mater. 20, 4494 (2008).

26. D. Gittard, A. Nguyen, K. Obata, A. Koroleva, R. J. Narayan, B.N. Chichkov, Biomed. Opt. Express 2, 3167 (2011).

27. A. Marino, C. Filippeschi, V. Mattoli, B. Mazzolai, G. Ciofani, Nanoscale 7, 2841 (2015).

28. S. R. Raghavan, H. J. Walls, S. A. Khan, Langmuir 16, 7920 (2000).

29. F. Kotz, K. Arnold, P. Risch, B. E. Rapp, Proc. SPIE 10804, 108040I (2018)

\section{References}




\section{References}

1. F. Klocke, A. McClung, C. Ader, 'Direct Laser Sintering of Borosilicate Glass', in Solid Freeform Fabrication Proceedings 2004, 214.

2. G. Marchelli, R. Prabhakar, D. Storti, M. Ganter, 'The guide to glass 3D printing: developments, methods, diagnostics and results ', Rapid Prototyping Journal 17, 187 (2011).

3. J. Luo, H. Pan, E. Kinzel, 'Additive manufacturing of glass', Journal of Manufacturing Science and Engineering 136, 061024 (2014).

4. M. Fateri, A. Gebhardt, 'Selective laser melting of soda-lime glass powder', International Journal of Applied Ceramic Technology 12, 53 (2015).

5. K. C. Datsiou, E. Saleh, F. Spirrett, R. Goodridge, I. Ashcroft, D. Eustice, 'Additive manufacturing of glass with laser powder bed fusion ', Journal of the American Ceramic Society 102, 4410 (2019)

6. J. Klein, M. Stern, G. Franchin, M. Kayser, C. Inamura, S. Dave, J. C. Weaver, P. Houk, P. Colombo, M. Yang, N. Oxman, 'Additive manufacturing of optically transparent glass ', 3D Printing and Additive Manufacturing. 2, 92 (2015).

7. J. Luo, L. J. Gilbert, C. Qu, R. G. Landers, D. A. Bristow, E. C. Kinzel, 'Additive manufacturing of transparent soda-lime glass using a filament-fed process', J. Manuf. Sci. Eng. 139, 061006 (2017).

8. D. T. Nguyen, C. Meyers, T. D. Yee, N. A. Dudukovic, J. F. Destino, C. Zhu, E. B. Duoss, T. F. Baumann, T. Suratwala, J. E. Smay, R. Dylla-Spears, 3DPrinted Transparent Glass ', Adv. Mater. 1701181 (2017).

9. M. Wozniak, T. Graule, Y. Hazan, D. Kata, J. Lis, 'Highly loaded UV curable nanosilica dispersions for rapid prototyping applications', Journal of the European Ceramic Society 29, 2259 (2009).

10. F. Kotz, K. Arnold, W. Bauer, D. Schild, N. Keller, K. Sachsenheimer, T. M. Nargang, C. Richter, D. Helmer, B. E. Rapp, 'Three-dimensional printing of transparent fused silica glass', Nature 544, 337 (2017).

11. F. Kotz, K. Plewa, W. Bauer, N. Schneider, N. Keller, T. Nargang, D. Helmer, K. Sachsenheimer, M. Schäfer, M. Worgull, C. Greiner, C. Richter, B. E. Rapp, 'Liquid Glass: A Facile Soft Replication Method for Structuring Glass', Adv. Mater. 28, 4646 (2016).

12. Y. Chu, X. Fu, Y. Luo, J. Canning, Y. Tian, K. Cook, J. Zhang, G.-D. Peng, 'Silica optical fiber drawn from 3D printed preforms', Opt. Lett. 44, 5358 (2019)

13. D.G. Moore, L. Barbera, K. Masania, A.R. Studart, 'Three-dimensional printing of multicomponent glasses using phase-separating resins', Nat. Mater. 19, 212 (2020).

14. I. Cooperstein, E. Shukrun, O. Press, A. Kamyshny, S. Magdassi, 'Additive manufacturing of transparent silica glass from solutions' ACS Appl. Mater. Interfaces 10, 18879 (2018)

15. J.C. André, 'From Additive Manufacturing to 3D/4D Printing 2: Current Techniques, Improvements and their Limitations', Wiley-ISTE, 2017.

16. S. Maruo, O. Nakamura, S. Kawata, 'Three-dimensional microfabrication with two-photon-absorbed photopolymerization', Opt. Lett. 22, 132 (1997).

17. J.C. André, A. Le Méhauté, O. De Witte, 'Dipsopsitif pour réaliser un modèle de pièce industrielle', patent FR2567668 (1984).

18. H.B. Sun, S. Matsuo, H. Misawa, 'Three-dimensional photonic crystal structures achieved with two-photon-absorption photopolymerization of resin', Appl. Phys. Lett. 74, 786 (1999).

19. J. Scrimgeour, D. N. Sharp, C. F. Blanford, O. M. Roche, R. G. Denning, A. J. Turberfield, 'Three-Dimensional Optical Lithography for Photonic Microstructures', Adv. Mater. 18, 1557 (2006).

20. R. A. Borisov, G. N. Dorojkina, N. I. Koroteev, V. M. Kozenkov, S. A. Magnitskii, D. V. Malakhov, A. V.Tarasishin, A. M. Zheltikov, 'Femtosecond two-photon photopolymerization: a method to fabricate optical photonic crystals with controllable parameters' Laser Phys. 8, 1105 (1998)

21. J. Serbin, A. Egbert, A. Ostendorf, B. N. Chichkov, R. Houbertz, G. Domann, J. Schulz, C. Cronauer, L. Fröhlich, M. Popall, 'Femtosecond laser-induced two-photon polymerization of inorganic-organic hybrid materials for applications in photonics', Opt. Lett. 28, 301 (2003).

22. H.-B. Sun, S. Kawata, 'Two-photon laser precision microfabrication and its applications to micro-nano devices and systems', J. Lightwave Tech. 21, 624 (2003).

23. S. Maruo, K. Ikuta, H. Korogi, 'Force-controllable, optically driven micromachines fabricated by single-step two-photon microstereolithography', J. of Microelectromechanical Systems 12, 533 (2003).

24. D. Wu, Q. D. Chen, L. G. Niu, J. N. Wang, J. Wang, R. Wang, H. Xia, H. B. Sun, 'Femtosecond laser rapid prototyping of nanoshells and suspending components towards microfluidic devices', Lab Chip 9, 2391S (2009).

25. P. Tayalia, C. R. Mendonca, T. Baldacchini, D. J. Mooney, E. Mazur, '3D cell-migration studies using two-photon engineered polymer scaffolds', Adv. Mater. 20, 4494 (2008).

26. D. Gittard, A. Nguyen, K. Obata, A. Koroleva, R. J. Narayan, B.N. Chichkov, 'Fabrication of microscale medical devices by two-photon polymerization with multiple foci via a spatial light modulator', Biomed. Opt. Express 2, 3167 (2011).

27. A. Marino, C. Filippeschi, V. Mattoli, B. Mazzolai, G. Ciofani, 'Biomimicry at the nanoscale: current research and perspectives of two-photon polymerization', Nanoscale 7, 2841 (2015).

28. S. R. Raghavan, H. J. Walls, S. A. Khan, 'Rheology of silica dispersions in organic liquids: new evidence for solvation forces dictated by hydrogen bonding', Langmuir 16, 7920 (2000).

29. F. Kotz, K. Arnold, P. Risch, B. E. Rapp; 'Next-generation 3D printing of glass: the emergence of enabling materials', Proc. SPIE 10804, 108040। (2018) 